\title{
Opening up the Solution Space: The Role of Analogical Thinking for Breakthrough Product Innovation
}

The final version of this manuscript is published in Creativity and Innovation Management, 17(2): 97-106.

The final publication is available at the following link at www.onlinelibrary.wiley.com:

http://onlinelibrary.wiley.com/doi/10.1111/j.1467-8691.2008.00475.x/pdf DOI: $10.1111 / \mathrm{j} .1467-8691.2008 .00475 . x$ http://dx.doi.org/10.1111/j.1467-8691.2008.00475.x

Please note that differences between this manuscript and the final publication may exist. In case of questions, please contact the corresponding author as indicated below. 


\title{
Oliver Gassmann, Marco Zeschky
}

\section{Opening up the solution space - the role of analogical thinking for break- through product innovation}

\begin{abstract}
The purpose of this paper is to investigate the approach of analogical thinking for product innovation. We collected data of projects from four engineering firms where analogical thinking was successfully applied for the development of breakthrough innovations. Results show that abstracting the problem by in-depth technical and contextual analysis is pivotal when searching for analogical solutions. Furthermore, chances for the identification of highly novel analogous solutions are increased if the problem is abstracted to the level of its structural similarities to other settings. We also found that the identification of structural similarities is supported when firms not only rely on the cognitive abilities of the individual but employ an active search based on abstract search terms. Based on these insights, we propose a process model for the development of product innovations by means of analogical thinking.
\end{abstract}




\section{Introduction}

When the BMW Group introduced their path-breaking man-machine interface iDrive in 2001 , they took advantage of an analogous solution from a non-automotive domain and integrated it in a single controlling device. The iDrive is a device for controlling a manifold of functions in luxury cars which were until then controlled by up to 200 different knobs and switches. The analogy was found in the joystick as an important device in the video game industry, and the respective knowledge was transferred and adapted to the specific requirements in the course of the development process.

Recent studies have emphasized the importance of analogies for radical product innovation (Keane, 1987; Dahl \& Moreau, 2002) and increased firm performance (Gavetti et al., 2005). Analogical thinking, particularly when applied across industry boundaries, may significantly contribute to the development of highly novel innovations (Holyoak \& Thagard, 1995) while simultaneously limiting the risks of uncertainty (De Bono, 1990). On the one hand, drawing analogies from an initial problem to distant but similar problem settings may reduce uncertainty as potential solutions have already proved to function in a similar context. On the other hand, non-obvious analogies may entail highly novel solutions because the combination of more distant pieces of knowledge is associated with higher innovative potential (Holyoak \& Thagard, 1995; Hargadon \& Sutton, 1997). In fact, "divergence and lack of shared experiences are critical for developing new ideas" (Majchrzak et al., 2004). From cognitive psychology perspective, analogical thinking entails the transfer of knowledge from one domain that usually already exists in memory to the domain to be explained (Gick \& Holyoak, 1983; Vosniadou \& Ortony, 1989). Management scholars have argued that the use of analogies typically includes the transfer of knowledge (Majchrzak et al., 2004), where knowledge acquired in one situation is applied to another (Argote \& Ingram, 2000). The ability to combine different pieces of knowledge ('combinative capability') for product innovation is a strategically significant resource to a competitive organization (Kogut \& Zander, 1992; Grant, 1996). 
The role and importance of analogies in problem solving has also been widely discussed by creativity researchers (Prince, 1970; Boden, 1990; Rickards, 1990; Csikszentmihalyi, 1996), and analogies are a central mechanism in many creativity techniques (Gordon, 1969; De Bono, 1990; Ceserani \& Greatwood, 1995). However, there is limited insight into how analogical thinking is enabled and applied at the level of the firm for product innovation. More aptly, literature lacks empirical insight in the origin of analogies, that is, how analogous problems and solutions are found in the first place (De Bono, 1990).

The aim of this paper is to show how analogical thinking is enabled and used for product innovation at the level of the firm. Thus, our research question is: 'How do firms enable and use analogical thinking, and what are its success factors for new product development?' We first review relevant literature on analogical thinking and illustrate four cases where firms have enabled and used analogical thinking for the development of breakthrough product innovations. We then discuss the cases and conclude with managerial implications for how to approach analogical thinking in a systematic manner.

\section{Analogical Thinking in Problem Solving}

The role and importance of analogies for innovation has mostly been investigated in product design and psychology literature (Dahl \& Moreau, 2002). However, scholars have recently also started to investigate the role of analogical thinking within the firm for strategy making (Nerkar \& Roberts, 2004; Gavetti et al., 2005; Gavetti \& Rivkin, 2005). Analogical thinking is a creative method for a problem that needs a solution. Analogical thinking happens if a familiar problem is used to solve a novel problem of the same type (Reeves \& Weisberg, 1994). Literature has argued that the identification of analogies is stimulated by rather specific problems (De Bono, 1990). Analogies can be drawn in different settings and directions. In some cases, a solution is found in one 
industry and applied to solve a problem in another industry. In other instances, the analogy is drawn from a solution looking for a problem (Gavetti et al., 2005). In all cases, the search for a solution is stimulated by a rather specific problem. Within this 'problemistic search' (Cyert \& March, 1992), analogies to settings quite similar to the original problem can be drawn, potentially providing a solution.

Cognitive scientists commonly agree that innovation entails reassembling elements from existing knowledge bases in a novel fashion (Gagne \& Shoben, 1997; Hampton, 1998). Thus, analogical thinking is a mechanism underlying creative tasks, in which people transfer information from a familiar setting and use it for the development of ideas in a new setting (Gentner \& Rattermann, 1993; Dahl \& Moreau, 2002). Similarity of concepts (such as problems or situations) at any level of abstraction is argued to enable analogical thinking (Keane, 1987; Ross, 1989; Reeves \& Weisberg, 1994; Holyoak \& Thagard, 1997). Thus, similarity of some basic elements between the source where the problem origins (i.e. the problem source) and the source where the analogy is found (i.e. the solution source) is a vital precondition for analogies to be identified. Similarity has also been described in a continuum from 'near' or 'surface' analogies to 'far' or 'structural' analogies (Dahl \& Moreau, 2002). Near analogies are much easier identified than far analogies, as near analogies often entail obvious surface similarities such as similar design while far analogies typically entail similarities in the structural relationships between source and target attributes. For instance, Dahl et al. (2002) illustrate the case of designing a new free-way system. A near analogy would entail to look at an already existing freeway system in another city, whereas a far analogy would entail to arrive at a solution by considering the human circulatory system. The distinction is important because near and far analogies require different types of information to be mapped and transferred. At near analogies both surface-level attributes (e.g. roads) and relations between the attributes (e.g. the flow of cars through the freeway) are mapped and transferred, while the lack of surface-level attributes at far analogies 
leaves the mapping to occur between common relations (Gentner, 1989; Ward, 1994). The example intuitively shows that far analogies are more difficult to identify and require more cognitive effort. The identification of far analogies requires the identification of similarities in the relational (vs. surface) structure between the problem and the solution source, which is often difficult when surface similarities are completely absent. However, if successfully implemented, far or structural analogies serve as the base for 'mental leaps' and can lead to radical innovation (Holyoak \& Thagard, 1995). On the other hand, if source and target share the same surface qualities, they often come from the same or close conceptual domain (Ward, 1994), which would lead to incremental innovation. However, surface and structural similarities are two ends of a continuum, and a clear distinction between them is difficult. In this paper, we refer to surface similarities when there are similarities in features such as product design and product features, and to structural similarities when there are similarities in the principal technological function and architecture of the product (Henderson \& Clark, 1990).

The use of analogies has also been widely discussed as a means of creative thinking for problem solving (Gordon, 1969; Prince, 1970; De Bono, 1990; Ceserani \& Greatwood, 1995; Amabile, 1996). Creativity and construction methods such as the 'theory of inventive problem solving' (TIPS) first invented by Altshuller and colleagues, lateral thinking (De Bono, 1990), and synectics (Gordon, 1969) all contain notions of analogical thinking as a central mechanism. Altshuller and colleagues found in their analysis of patents that most inventions were based on a rather small number of generally applicable principal solutions (Mann, 2001). Thus, in case of technical problems, TIPS supports solution finding by systematically pointing out alternative and analogical technical solution principles. A central theme in De Bono's (1990) lateral thinking is breaking with established thinking patterns of the human mind and exposing the mind to discontinuities. De Bono argues that the deliberate introduction and proper pursuit of an analogue problem not only takes up less time in finding solutions, but will eventually lead to pro- 
cesses, functions, and relationships which are then transferred back to the original problem 'to see if they fit or what ideas they set off' (De Bono, 1990). Synectics is based on the 'force-fitting' or recombination of knowledge that appear to have no relations. However, by recombination, the individual is detached from the problem and forced to relate the new knowledge to the original problem to enable creative solutions (Gordon, 1969).

\section{Research Methodology}

The purpose of this paper is to show how firms enable and use analogical thinking for product innovation. Because of the lack of empirical insights in how analogical thinking is enabled and applied at the level of the firm, a qualitative case study approach is employed (Eisenhardt, 1989; Yin, 2003). We employed a multiple-case study to obtain richer insight into how different settings may influence the approach and effect of analogical thinking. The case firms were identified in the course of a two year research project focusing on firms' use of analogies for radical new product innovation. Out of a sample of 18 companies that participated in the research project, we selected a purposive sample of four companies which met the criteria that they

- were engineering companies

- had engaged in breakthrough product innovation based on the use of analogies.

The case firms are based in Switzerland and Austria where they also develop and manufacture. As is typical for engineering companies, problems mainly concern the technical improvement of existing products. Therefore, the 'problem' is typically identical with the product, and we sue both terms interchangeably. We adopt Chandy and Tellis' (1998) taxonomy of innovations along the technology and market domains (see table 1), which is consistent with many other definitions of the degree of novelty of an innovation (see Garcia \& Calantone, 2002). 
Accordingly, incremental innovations involve relatively minor changes in technology and customer benefit. Market breakthroughs are based on core technologies but provide substantially higher customer benefits. Technological breakthroughs do not provide higher customer benefit, but involve a substantially different technology. Radical innovations involve substantially new technology and provide substantially higher customer benefits (Sorescu et al., 2003).

We collected data by means of personal in-depth interviews, archival documents, and passively participated in workshops of current development projects with senior managers and R\&D employees. We organized the interviews by consistently using one and the same semi-structured interview guide to ensure the reliability of the results (Yin, 2003). The interview guide comprised questions about what actions were taken during the problem solving process, and thus how the analogy was ultimately identified. The questions concentrated on facts and events within the problem solving process rather than on respondents' interpretations (Eisenhardt, 1989). These personal interviews lasted between 60 and 140 minutes and were tape-recorded and transcribed. Table 1 provides a brief overview of the case firms.

<insert table 2 about here>

\section{Case Studies: Analogical Thinking in Breakthrough Product Innovation}

\section{Case 1: AlpineCo}

AlpineCo had the problem that the skis were difficult to control at certain speeds. Analyzing the cause, R\&D found that the ski was developing a resonance frequency at high speeds which caused the ski to vibrate. During the phase of intense occupation with analyzing the problem, the head of R\&D and three colleagues were delving into the question how the vibration could be damped or eliminated. From his background as a 
mechanical engineer, the head of R\&D knew that vibrations were a recurring problem in settings such as machine or building construction. With the terms 'vibration', 'damping', and 'cushioning' unconsciously in mind, the team then decided to search for industries and applications where damping or elimination of vibrations were a problem: "we were actively looking for analogous solutions". However, initial search efforts were in vain because of a too large search scope, as the $R \& D$ team was searching for anything that had to with vibrations. The search was only successful when one team member proposed to limit the search scope to include frequencies only above 1800 hertz, as this was the range of frequency found in the vibrating ski. This frequency is typically found in acoustics, and AlpineCo ultimately found a viable solution at an inventor who had for years researched on the elimination of undesirable frequencies of bowed instruments. Also, the solution proved to be easily transferable, as the material used to filter undesired frequencies of the bowed instruments could easily be adapted to the skis. "It's a simple idea and easily applicable, and did not require any additional investments" (head of R\&D). AlpineCo then applied the solution to its own demands by developing an extra layer in the ski with similar structure and material like in the bowed instruments and incorporated it into the ski. This technology is termed "frequency tuning" and today found in virtually every ski.

\section{Case 2: AluCo}

For a long time, AluCo had been looking for alternative approaches for how to improve its crash management system (CMS) (consisting of the front beam and two crashboxes which is mounted to the longitudinal chassis beams of a car). Somewhat frustrated with the hitherto 'conventional' approach, AluCo management realized that mere optimization of materials and tweaking geometric designs would not result in the major advancement that they hoped for: "we have been doing this for decades now, and I believe our engineers have become too short-sighted to look beyond the own nose" (head of future technologies). Before "prematurely jumping to solutions" (head of future 
technologies), a team of four R\&D employees engaged in an in-depth investigation of the current crashbox. They particularly focused on detailed understanding of the product function both from a technological view and customer utility point of view. In subsequent workshops, the team first analyzed and described the technological function of the crashbox in terms such as "protecting the car's longitudinal carrier from damage" and later in terms such as "gliding grid structures in the material". In the course of the analysis AluCo developed key terms such as 'energy absorption' and 'transformation of kinetic energy'. With these terms, AluCo build associations to different kinds of technologies, applications and industries where the absorption of energy was crucial. AluCo's R\&D then started to search the internet with focus on the previously developed key terms. By means of this, they identified several promising technologies new to their industry, which today are subject for further development.

\section{Case 3: TextileCo}

TextileCo faced the problem that the speed of the material displacement was different from the speed of the sewing foot, which resulted in inhomogeneous stitch-lengths and spaces. Thus, first activities aimed at synchronizing the speed of the material displacement with the speed of the sewing foot. Analyzing how the displacement could be gauged under the given spatial constraints, TextileCo's R\&D concluded that the displacement of the material had to be gauged with high precision because of the high speed of the sewing foot. As gauging was outside their competence, TextileCo agreed on looking for external solutions. A team of five R\&D members started looking for solutions that were related to what TextileCo called "real-time gauging". In this, they approached an external technology service provider, who ultimately provided AluCo with the optical sensor of a conventional computer mouse as a solution. The service provider had previously worked on another project where feedback-loops played an important role and where a very similar sensor technology was applied. As the R\&D leader said, "without the service provider we had never come up with such a brilliant and simple 
solution, it took us only 18 months from problem formulation to market introduction, which is about half the time we usually need." TextileCo adapted the mouse sensor chip to its specific requirements and enhanced it so it would even recognize very smooth or dark fabrics. As a result, because of the automation even beginners are now able to quilt genuine artwork of high quality. This had previously been a domain only for experienced quilters, and implementing the new technology allowed TextileCo to tap a new and fast growing market.

\section{Case 4: PipesCo}

The piping division of PipesCo has deep know-how in production techniques such as welding or gluing in combination with material optimization for the joining of pipes. As the industry is characterized by long product life-cycles, conventional strategy has been constant improvement of existing technologies and products. One day an R\&D employee was watering the flowers in his garden, and realized that the hose and the sprinkler head were connected via a clicking-system: "It was a lucky accident. The basic principle is the same, it's about a medium flowing through a pipe, only the way the pipes are connected is different" (R\&D employee). He introduced the idea in the company, and preliminary assessments convinced the CTO to pursue the idea, both because of the simplicity of the technology which would tremendously facilitate the joining of large pipes in construction and because of the enormous cost savings involved with the new technology. In the eyes of the CTO "it was a revolutionary development, but actually we simply incrementally advanced what was already known in another industry. The biggest challenge was to adapt the solution to the existing requirements in terms of pressure, safety, and durability." Today, the clicking-technology has prevailed and led to significant competitive advantage for PipesCo.

\section{Discussion}


Considering the definition of newness of innovation according to Chandy and Tellis (1998), the use of analogies of the case firms has resulted in the development of technological breakthroughs (AlpineCo, AluCo, PipesCo) and radical innovations (TextileCo). Despite similar in its highly innovative character, the cases reveal differences in how the analogies were identified, and that analogical thinking is enabled both by pure cognitive abilities (PipesCo) and by systematic effort (AlpineCo, AluCo, TextileCo). In the case of PipesCo, the identification of the analogy might be owed to serendipity in the first step, and to the ability of the R\&D employee to relate the situation to a problem the firm was facing in the second step. In contrast, the other cases show that the identification of the analogy was only enabled after delving into the problem structure and initiating a deliberate search effort for analogous solutions.

We furthermore find that mere identification of the analogy is not sufficient but that particularly in the case of structural analogies - firms need strategic intent (Chandy \& Tellis, 1998; Herrmann et al., 2007), that is, the will to question own technologies and the will to adapt new knowledge. Also, the mere identification of the analogous solution is not sufficient, as the transfer of relevant knowledge and its adaptation to the own problem context are vital for the 'idea' to become an innovation. The findings are discussed in the following; table 3 provides an overview of how the analogy was identified and the characteristics of the analogies.

<insert table 3 about here>

\section{Strategic Intent}

In analyzing the cases, it shows that the will to break with conventional boundaries is paramount when searching for non-obvious and solutions of higher novelty. As entirely new technologies often serve as substitutes, existing technologies and competencies might be jeopardized, as is particularly the case at AluCo and PipesCo. Thus, the will to question own products and technologies is vital for successful radical innovations 
(Herrmann et al., 2007). With respect to analogical thinking, our findings coincide with the research of Majchrzak and Neece (2004) on knowledge reuse who found that in order to use analogies, the reusers in the more innovative cases needed to be aware of and open to non-traditional approaches that might lead to greater levels of innovation. All firms were willing and open to look for solutions that were neither developed internally nor established in their industry. Openness to external developments and innovations has been found a critical success factor for firms in technology-intensive industries (Chesbrough, 2003; Gassmann, 2006). Furthermore, TextileCo integrated external experts for the identification of the analogous solution, an approach which is considered highly beneficial for innovation (von Hippel, 1986). Thus, as analogous solutions typically originate outside known environments, an open attitude is pivotal for analogical thinking to be successful (Katz \& Allen, 1982).

\section{Cognitive Abilities, Problem Analysis, and Deliberate Search}

The identification of analogies typically depends on the cognitive abilities and the personal experiences of the individual (Gentner \& Rattermann, 1993; Reeves \& Weisberg, 1993; Dahl \& Moreau, 2002; Cummings \& Teng, 2003), and analogies to some target can only be found if the individual has had prior exposure to at least some elements of the target setting (Gick \& Holyoak, 1980; Reeves \& Weisberg, 1993). Thus, the successful identification of analogies also depends on the type of the analogy, i.e. if the problem and solution source share surface or structural similarities (Dahl \& Moreau, 2002). In the case of PipesCo, the identified analogy might be considered a surface analogy because problem and solution source share very similar physical characteristics. Thus, despite its surface character, the analogy led to a technological breakthrough innovation for PipesCo as it involved tremendous cost savings and introduced a new technology to the industry (Ward, 1994; Chandy \& Tellis, 1998). The example shows that also surface similarities can result in innovations of higher novelty (Holyoak \& Thagard, 1995; Hargadon \& Sutton, 1997). 
However, in all other cases the firms may have required more cognitive abilities to identify the analogy. Here, the analogies were based on rather structural similarities and were not immediately visible as in the case of PipesCo. The firms identified the analogy only when a) in a first step analyzing the problem in detail, and b) in a second step embarking on a deliberate search effort to find analogous solutions. The detailed problem analysis entailed that these firms carried out an in-depth analysis regarding the technical and contextual functions of the product. The technical analyses included re-building a deep understanding of the technological function and the interrelation between single components of the product. Contextual analysis included building a profound understanding of the true customer benefits, and all firms furthermore ensured to analyze and understand the identified analogy in its original application context (Leonard \& Rayport, 1997; Beckman \& Barry, 2007).

The joint analysis of technical and contextual functions subsequently increased the degree of abstraction from the original problem, as more and more structural elements of the problem were identified. This enabled the firms to identify the underlying mechanisms (i.e. the structure) of the problem, allowing them to look beyond mere superficial similarities (Fernandez \& Montes, 1999). As a consequence, the amount of analogical ideas increased with each additional abstraction from the original problem. This was particularly obvious in the case of AluCo. AluCo first analyzed the problem to the point of 'gliding grid structures in the material', before arriving at terms such as 'energy absorption'. The difference between both types of terms is the degree of abstraction, the first one being a quite specific technical description, the latter a description of the underlying purpose of the product. AluCo realized that it did not primarily matter how the kinetic energy was transformed, but that it was turned into another safer type of energy. Thus, the more abstract the description became, the more solutions and also the more structural similarities could be identified (Dahl \& Moreau, 2002). When looking at struc- 
tural analogies, the quality of the information might be more tacit in contrast to superficial similarities where the information is more explicit (Nonaka, 1994). Similarly, abstracting from the problem required the firms to understand how the problem is structured, implying that problem know-how might be more important than mere problem knowledge for the development of more radical innovations (Kogut \& Zander, 1992).

Thus, by abstracting the original problem to its structural relationships, the space for potential solutions is opened up (figure 1), and the use of cognitive abilities is enabled or facilitated.

<insert figure 1 about here>

Problem abstraction as carried out by the firms might be an effective means for arriving at a proper problem formulation, which has been found vital for successful product innovation (Cooper, 1999; Ward, 2004). In this regard, 'problems can be defined very concretely or abstractly, with the former leading to less novelty but more familiarity' (Ward, 2004).

\section{Knowledge Creation and Adaptation Development}

Transfer of relevant knowledge to the target problem was in all cases successful, however, the cases of AlpineCo, TextileCo and PipesCo show that further development is necessary to adapt to the original problem's requirements (Cummings \& Teng, 2003). The identified analogies were mostly perceived as simple but powerful solutions, which supports the assumption that analogies entail limited risks while simultaneously having great impact in terms of radical innovations. The case of PipesCo shows that despite the surface analogy the target solution had to be adapted to the existing requirements of the source problem, which according to the CTO constituted the biggest problem. In order to arrive at a workable solution, all firms had to analyze and understand the information found in the solution source which included the creation of new knowledge in 
the analogizing firm. Understanding the information of the solution source subsequently enabled the firms to filter the knowledge pieces most relevant for them. For example, in the case of AlpineCo, the found analogous solution could not be transferred in its entirety, but relevant knowledge about the grid-material was transferred and afterwards applied to the skis with an individually calculated grid structure.

The cases show that analogical thinking does not happen merely by accident but is supported by means of a systematic approach. Based on the insights from the cases we propose a generic process we call $A^{4}$-Innovation Process (figure 2). Its purpose is to provide firms with a structured approach for how analogical thinking might be enabled and applied for breakthrough product innovation.

<insert figure 2 about here>

\section{Conclusion}

The aim of this paper is to show how firms enable and use analogical thinking for the development of product innovation. Thus, we aim to extend literature on analogical thinking by providing empirical insights on how firms enable and use analogies. We found that firms must be open-minded for external solutions and willing to challenge own technologies as a premise for analogical thinking to work. Therefore, top management must foster the search for external solutions and be willing to cannibalize established products and technologies. In this, analogical thinking might be a powerful approach to identify new and non-obvious technological solutions with limited risk and cost. Apart from firms' strategic decision to be open for external innovations, we found the following aspects to be particularly important:

- Firms must establish a deep understanding of the problem and context in which the problem operates. This requires an in-depth analysis of the problem both from a technological and contextual perspective. Such analysis leads to subsequent ab- 
straction from the problem, allowing for abstract search terms to be generated. These tasks might be difficult for firms who have established products, as existing technologies, competencies and conventional mindsets are not easily overcome.

- Since the identification of both surface and structural analogies between different settings is facilitated when there has been prior exposure to both settings, the firm must establish ways to explore domains which differ from the own application context (Nelson \& Winter, 1982; March, 1991; Crossan \& Bedrow, 2003). This is particularly true as the cases show that even without prior exposure analogies can be found if a deliberate search effort based on abstract search terms is employed.

- Firms must understand the context of the analogous solution in order to evaluate what knowledge is valuable and thus is subject for transfer. Failure to do so might lead to the premature identification of a seemingly valuable analogy, leading to the adaptation of useless knowledge.

With the $A^{4}$-Innovation Process we aim to provide a structured approach for the identification of analogical solutions for the development of breakthrough product innovation. The $A^{4}$-Innovation Process is targeting the early innovation challenges in how to find highly novel solutions. First experience in applying this process with five engineering firms in different industries has been very positive and encouraging. In particular, these firms found that by applying the approach they arrived earlier at better solutions, compared to their 'conventional' problem-solving approach The outlined process has particular strength in the combination of existing knowledge in the problem source and experience with the solution source for creating new solutions in the own industry. We invite researchers to further test this process with a larger empirical sample across different industries for improved validation and to extend the discussion on analogical thinking for radical new product innovation. 


\section{Acknowledgements}

The authors would like to thank Jeff Butler and the anonymous reviewers for their valuable comments. 


\section{References}

Amabile, T. M. (1996). Creativity in Context. Boulder, Westview Press.

Argote, L. and P. Ingram (2000). "Knowledge Transfer: A Basis for Competitive Advantage in Firms." Organizational Behavior and Human Decision Processes 82(1): 150.

Beckman, S. L. and M. Barry (2007). "Innovation as a Learning Process: Embedding Design Thinking." California Management Review 50(1): 25.

Boden, M. A. (1990). The creative mind. Myths \& Mechanisms. London, Weidenfeld and Nicholson.

Ceserani, J. and P. Greatwood (1995). Innovation \& Creativity. London, Kogan Page.

Chandy, R. K. and G. J. Tellis (1998). "Organizing for Radical Product Innovation: The Overlooked Role of Willingness to Cannibalize." Journal of Marketing Research (JMR) 35(4): 474.

Chesbrough, H. (2003). Open Innovation. The New Imperative for Creating and Profiting from Technology. Boston, Harvard Business School Press.

Cooper, R. G. (1999). "From Experience: The Invisible Success Factors in Product Innovation." Journal of Product Innovation Management 16(2): 115.

Crossan, M. M. and I. Bedrow (2003). "Organizational Learning and Strategic Renewal." Strategic Management Journal 24(11): 1087.

Csikszentmihalyi, M. (1996). Creativity. Flow and the Psychology of Discovery and Invention. New York, HarperCollins.

Cummings, J. L. and B.-S. Teng (2003). "Transferring R\&D knowledge: the key factors affecting knowledge transfer success." Journal of Engineering \& Technology Management 20(1/2): 39.

Cyert, R. and J. G. March (1992). A behavioral theory of the firm. Cambridge, Massachusetts, Blackwell Publishers.

Dahl, D. W. and P. Moreau (2002). "The Influence and Value of Analogical Thinking During New Product Ideation." Journal of Marketing Research (JMR) 39(1): 47.

De Bono, E. (1990). Lateral Thinking for Management. London, Penguin Books Ltd.

Eisenhardt, K. M. (1989). "Building theories from case study research." Academy of Management Review 14(4): 532-550.

Fernandez, E. and J. M. Montes (1999). "Competitive strategy in technological knowledge imitation." International Journal of Technology Management 18(5-8): 535.

Gagne, C. L. and E. J. Shoben (1997). "Influence of thematic relations on the comprehension of modifier-noun combinations." Journal of Experimental Psychology: Learning, Memory, and Cognition 23(1): 71.

Garcia, R. and R. Calantone (2002). "A critical look at technological innovation typology and innovativeness terminology: a literature review." Journal of Product Innovation Management 19(2): 110.

Gassmann, O. (2006). Opening up the innovation process: towards an agenda. R\&D Management. 36(3): 223.

Gavetti, G., D. A. Levinthal and J. W. Rivkin (2005). "Strategy making in novel and complex worlds: the power of analogy." Strategic Management Journal 26(8): 691.

Gavetti, G. and J. W. Rivkin (2005). How Strategists Really Think. Harvard Business Review, Harvard Business School Publication Corp. 83: 152.

Gentner, D. (1989). The Mechanisms of Analogical Transfer. Similarity and Analogical Reasoning. S. Vosniadou and A. Ortony. Cambridge, Cambridge University Press.

Gentner, D. and M. J. Rattermann (1993). "The roles of similarity in transfer: Separating retrievability from inferential soundness." Cognitive Psychology 25(4): 524. 
Gick, M. L. and K. J. Holyoak (1980). "Analogical problem solving." Cognitive Psychology 12(3): 306.

Gick, M. L. and K. J. Holyoak (1983). "Schema Induction and Analogical Transfer." Cognitive Psychology 15: 1-38.

Gordon, W. J. J. (1969). Synectics - the Development of Creative Capacity. New York, Harper and Row.

Grant, R. M. (1996). "Prospering in Dynamically-competitive Environments: Organizational Capability as Knowledge Integration." Organization Science 7(4): 375.

Hampton, J. A. (1998). "Conceptual combination: Conjunction and negation of natural concepts." Memory \& Cognition 25(6): 888.

Hargadon, A. and R. I. Sutton (1997). "Technology Brokering and Innovation in a Product Development Firm." Administrative Science Quarterly 42(4): 716.

Henderson, R. M. and K. B. Clark (1990). "Architectural Innovation: The Reconfiguration of Existing Product Technologies and the Failure of Established Firms." Administrative Science Quarterly 35(1): 9.

Herrmann, A., O. Gassmann and U. Eisert (2007). "An empirical study of the antecedents for radical product innovations and capabilities for transformation." Journal of Engineering \& Technology Management 24(1/2): 92.

Holyoak, K. J. and P. Thagard (1995). Mental Leaps: Analogy in Creative Thought. Cambridge, MA, MIT Press.

Holyoak, K. J. and P. Thagard (1997). "The analogical mind." American Psychologist 52(1): 35.

Katz, R. and T. J. Allen (1982). "Investigating the Not Invented Here (NIH) syndrome: A look at the performance, tenure, and communication patterns of $50 \mathrm{R} \& \mathrm{amp}$; D Project Groups." R\&D Management 12(1): 7-20.

Keane, M. (1987). "On retrieving analogues when solving problems." The Quarterly Journal of Experimental Psychology Section A 39(1): 29 - 41.

Kogut, B. and U. Zander (1992). "Knowledge of the firm, combinative capabilities, and the replication of technology." Organization Science 3(3): 383.

Leonard, D. and J. F. Rayport (1997). "Spark innovation through empathic design." Harvard Business Review 75(6): 102.

Majchrzak, A., L. P. Cooper and O. E. Neece (2004). "Knowledge Reuse for Innovation." Management Science 50(2): 174.

Mann, D. (2001). "An Introduction to TRIZ: The Theory of Inventive Problem Solving." Creativity \& Innovation Management 10(2): 123.

March, J. G. (1991). "Exploration and Exploitation in Organizational Learning." Organization Science 2(1): 71.

Nelson, R. R. and S. G. Winter (1982). An evolutionary theory of economic change. Cambridge, Belknap Press of Harvard University Press.

Nerkar, A. and P. W. Roberts (2004). "Technological and product-market experience and the success of new product introductions in the pharmaceutical industry." Strategic Management Journal 25(8-9): 779-799.

Nonaka, I. (1994). "A Dynamic Theory of Organizational Knowledge Creation." Organization Science 5(1): 14.

Prince, G. M. (1970). The Practice of Creativity. New York, Macmillan.

Reeves, L. M. and R. W. Weisberg (1993). "Abstract versus concrete information as the basis for transfer in problem solving: Comment on Fong and Nisbett (1991)." Journal of Experimental Psychology: General 122(1): 125.

Reeves, L. M. and R. W. Weisberg (1994). "The role of content and abstract information in analogical transfer." Psychological Bulletin 115(3): 381. 
Rickards, T. (1990). Creativity and Problem Solving at Work. Hants, England, Gower Publishing Company Ltd.

Ross, B. H. (1989). "Distinguishing types of superficial similarities: Different effects on the access and use of earlier problems." Journal of Experimental Psychology: Learning, Memory, and Cognition 15(3): 456.

Sorescu, A. B., R. K. Chandy and J. C. Prabhu (2003). "Sources and Financial Consequences of Radical Innovation: Insights from Pharmaceuticals." Journal of Marketing 67(4): 82.

von Hippel, E. (1986). "Lead Users: A Source of Novel Product Concepts." Management Science 32(7): 791.

Vosniadou, S. and A. Ortony (1989). Similarity and analogical reasoning: a synthesis. Similarity and analogical reasoning. S. Vosniadou and A. Ortony. Cambridge, Cambridge University Press: 1-17.

Ward, T. B. (1994). "Structured Imagination: the Role of Category Structure in Exemplar Generation." Cognitive Psychology 27(1): 1.

Ward, T. B. (2004). "Cognition, creativity, and entrepreneurship." Journal of Business Venturing 19(2): 173.

Yin, R. K. (2003). Case study research: Design and methods. Thousand Oaks, CA, Sage Publications. 